\title{
Development of a Simplified Protocol for Administration of $20 \%$ Magnesium Sulphate for Prophylaxis and Treatment of Eclampsia
}

\author{
Lynne Palmer and Brandi D Newby
}

\begin{abstract}
Background: Magnesium sulphate is a high-risk medication that is used extensively for prophylaxis and treatment of eclampsia. To accommodate recommendations related to fluid restrictions and patient safety, a protocol was developed for the administration of $20 \%$ magnesium sulphate.
\end{abstract}

Objectives: To determine whether administration of $20 \%$ magnesium sulphate increased the risk of phlebitis relative to $2 \%$ to $8 \%$ magnesium sulphate solutions, to determine if the institution's protocol for administration of $20 \%$ magnesium sulphate reduced errors during administration, and to identify strategies to further reduce potential errors.

Methods: A retrospective chart audit was undertaken for patients who had received magnesium sulphate for prophylaxis of eclampsia from December 2004 to December 2007. A failure mode and effect analysis was used to identify additional safety strategies.

Results: A total of 47 patients received magnesium sulphate according to the old administration protocol ( $2 \%$ to $8 \%$ solution) and 29 according to the new protocol ( $20 \%$ solution). No evidence of phlebitis was documented for any of these 76 patients. A few errors occurred with changes in rates or concentrations and because of failure to reset the pump after the loading dose, but there was no documented harm to any of the patients. Strategies to further reduce errors in the administration of magnesium sulphate included development of preprinted orders, use of $20 \%$ magnesium sulphate for all infusion rates, changes to pump settings to enable use of fractional infusion rates, preparation of magnesium sulphate in mini-bags in the pharmacy, double-check of pump settings by nurses, anesthesiology consult, and distribution of protocols to all areas in the hospital (to limit errors associated with patient transfers).

Conclusions: There was no documented phlebitis, and fewer errors occurred when $20 \%$ magnesium sulphate was used. Several additional strategies were identified to reduce errors in the administration of this high-risk medication.

Key words: patient safety, magnesium sulphate, pre-eclampsia, eclampsia

Can J Hosp Pharm 2009;62(6):490-495

\section{RÉSUMÉ}

Contexte : Le sulfate de magnésium est un médicament à haut risque qui est utilisé à grande échelle dans le traitement prophylactique et curatif de l'éclampsie. Pour incorporer des recommandations ayant trait aux restrictions liquidiennes et à la sécurité des patientes, un protocole a été élaboré pour l'administration du sulfate de magnésium à $20 \%$.

Objectifs : Déterminer si l'administration d'une solution de sulfate de magnésium à $20 \%$ augmentait le risque de phlébite par rapport à des solutions de sulfate de magnésium entre $2 \%$ et $8 \%$ et si le protocole d'administration de sulfate de magnésium à $20 \%$ de l'établissement réduisait les erreurs d'administration, et définir des stratégies visant à réduire davantage les erreurs potentielles.

Méthodes : Une analyse rétrospective des dossiers médicaux des patientes qui avaient reçu du sulfate de magnésium comme traitement prophylactique de l'éclampsie entre décembre 2004 et décembre 2007 a été réalisée. Une analyse des modes de défaillance et de leurs effets a servi à déterminer des stratégies de sécurité supplémentaires.

Résultats : Un total de 47 patientes ont reçu du sulfate de magnésium selon l'ancien protocole d'administration (solution de $2 \%$ à $8 \%$ ) et 29 conformément au nouveau protocole (solution à $20 \%$ ). Aucun cas de phlébite n'a été documenté chez aucune des 76 patientes. Quelques erreurs sont survenues lors de modifications de débit ou de concentrations ou étaient attribuables à la non-réinitialisation de la pompe après l'administration de la dose de charge, mais les patientes n'ont subi aucun tort. Les stratégies visant à réduire davantage les erreurs d'administration du sulfate de magnésium incluaient le développement d'ordonnances préimprimées, l'utilisation de sulfate de magnésium à $20 \%$ pour tous les débits de perfusion, la modification des réglages de la pompe pour permettre l'utilisation des débits de perfusion fractionnaires, la préparation de minisacs de sulfate de magnésium en pharmacie, la vérification en double du réglage de la pompe par le personnel infirmier, la consultation d'un anesthésiologiste et la distribution de protocoles à tous les secteurs de l'hôpital (pour limiter les erreurs associées au transfert des patientes).

Conclusions : Aucun cas de phlébite n'a été documenté et moins d'erreurs sont survenues avec le sulfate de magnésium à $20 \%$. Plusieurs autres stratégies ont été définies pour réduire les erreurs d'administration de ce médicament à haut risque.

Mots clés : sécurité du patient, sulfate de magnésium, prééclampsie, éclampsie

[Traduction par l'éditeur] 


\section{INTRODUCTION}

The British Columbia Reproductive Care Program Health Program) and the Society of Obstetricians and Gynaecologists of Canada published new guidelines for the management of hypertensive disorders of pregnancy in June 2006 and March 2008, respectively. ${ }^{1,2}$ About 5.6\% of pregnancies in British Columbia are complicated by hypertensive disorders of pregnancy, and of these, $2 \%$ are complicated by eclampsia or seizures. ${ }^{1}$ Pre-eclampsia, defined as gestational hypertension with proteinuria and/or adverse conditions typical of end-organ dysfunction, occurs in $19 \%$ of pregnant patients with hypertensive disorders of pregnancy. ${ }^{1}$ Magnesium sulphate is recommended as the first-line medication for prophylaxis and treatment of eclampsia. The loading dose is $4 \mathrm{~g}$ IV over 20 to $30 \mathrm{~min}$, followed by a maintenance dose of $1 \mathrm{~g} / \mathrm{h}$ by continuous infusion for $24 \mathrm{~h}$ or until $24 \mathrm{~h}$ after delivery, whichever is later. For patients with recurrent seizures, the BCRCP recommended an additional bolus of magnesium sulphate $2 \mathrm{~g}$ IV and an increase in the maintenance infusion rate to $1.5 \mathrm{~g} / \mathrm{h} .{ }^{1}$ In addition, to minimize iatrogenic pulmonary edema, the BCRCP guidelines suggested a maximum rate of IV administration of $80 \mathrm{~mL} / \mathrm{h}$ from all sources. ${ }^{1}$ Because many patients with pre-eclampsia or eclampsia require additional IV fluids for administration of antihypertensive medications and oxytocin, it can be challenging to meet these fluid restrictions. At the authors' hospital, magnesium sulphate was usually administered at a concentration of $2 \%$ to $8 \%$ at IV rates up to $100 \mathrm{~mL} / \mathrm{h}$. However, the maximum recommended concentration of magnesium sulphate for IV infusion is $20 \%$; as such, the hospital could potentially use higher concentrations to help in achieving the recommended fluid restriction.

Magnesium sulphate has been identified as a high-risk medication with potential to harm both mother and fetus. ${ }^{4}$ Simpson and Knox ${ }^{5}$ reported 7 deaths in their database study of 52 cases involving inadvertent overdose of magnesium sulphate. Recommendations to improve patient safety with high-risk medications, specifically magnesium sulphate, have included standardized processes for ordering the medication, use of pump technology to limit infusion rates and volumes, specification of parameters for patient monitoring in magnesium sulphate administration protocols, use of separate bags for bolus and maintenance infusions, and use of volumes less than $1000 \mathrm{~mL}$ to avoid confusion with the medication-free primary solution. ${ }^{4,5}$

In July 2006, a new administration protocol for $20 \%$ magnesium sulphate was developed and implemented at the authors' hospital to incorporate recommendations from the BCRCP guidelines and the patient safety literature. ${ }^{1,45}$ However, because the $20 \%$ concentration of magnesium sulphate was much higher than the $2 \%$ to $8 \%$ concentrations used previously, there were concerns about a potential increase in the incidence of phlebitis. The incidence of phlebitis associated with magnesium sulphate in obstetric patients was unknown. The primary objective of this study was to determine if the risk of phlebitis was greater with the $20 \%$ magnesium sulphate solution than with the $2 \%$ to $8 \%$ solutions. Additional objectives were to determine if the new protocol for $20 \%$ magnesium sulphate reduced administration errors and to identify strategies to further reduce potential errors.

\section{METHODS}

A retrospective chart audit was conducted for patients who received magnesium sulphate at the authors' hospital between December 2004 and December 2007. To identify the patients who had received magnesium sulphate, a list was generated from the British Columbia Perinatal Database Registry of obstetric patients who had received any antihypertensive medication while admitted to the authors' hospital during the study period. We used International Classification of Diseases (10th revision) codes for HELLP syndrome (hemolysis, elevated liver enzyme levels, and low platelet count) and eclampsia to ensure that these patients were included in the chart review. Patients from this list who had received magnesium sulphate for prophylaxis or treatment of eclampsia were included in the study. The new administration protocol group consisted of patients admitted between July 2006 and December 2007. An equal number of charts with the same criteria but for patients treated before July 2006 was screened to create the old administration protocol group. All of the patients who received magnesium sulphate for prophylaxis or treatment of seizure during the study period constituted the convenience sample of patients for this study.

Patients in the old administration protocol group received magnesium sulphate $2 \%$ to $8 \%$ (exact concentration as specified by the physician). The nurse prepared the ordered solution by withdrawing the appropriate volume of 50\% magnesium sulphate and adding that to $1 \mathrm{~L}$ of a solution of two-thirds dextrose 5\% in water (D5W) and one-third $0.9 \%$ sodium chloride (normal saline). The nurse then used an infusion rate chart to program the pump to deliver the prescribed loading dose and the maintenance dose. The same bag of magnesium sulphate was used for the loading dose and the maintenance dose, with the infusion rate being adjusted at the end of the loading dose. The new administration protocol group received $20 \%$ magnesium sulphate. The nurse prepared the solution by adding $50 \mathrm{~mL}$ of $20 \%$ magnesium sulphate to an empty ViaFlex bag (Baxter Healthcare Corporation, Deerfield, Illinois) without further dilution. The nurse then used an infusion rate chart to program the pump to deliver the prescribed loading dose and maintenance dose. Separate bags 
were used for the loading dose and the maintenance dose. If an infusion rate of $1.5 \mathrm{~g} / \mathrm{h}$ was ordered, the $20 \%$ solution had to be diluted by addition of $10 \mathrm{~mL} \mathrm{D} 5 \mathrm{~W}$ to the $50 \mathrm{~mL}$ of magnesium sulphate, because the infusion pump was unable to deliver solutions at fractional infusion rates. All vials of 50\% magnesium sulphate were taken from ward stock.

Ethics approval was obtained from the Fraser Health Research Ethics Board. Descriptive statistics were used for reporting outcomes for the 2 groups of patients. The following outcomes were assessed: signs of phlebitis (or documentation of erythema, warmth, pain, burning, or swelling along the vein), evidence of extravasation of IV solution into surrounding tissue, efficacy of magnesium (indicated by occurrence of eclampsia), toxic effects of magnesium (indicated by occurrence of any of the following: loss of deep tendon reflexes, respiratory depression, need for calcium gluconate, or magnesium level greater than $3.5 \mathrm{mmol} / \mathrm{L}$ ), concentration of magnesium sulphate administered, dose of magnesium administered, duration of magnesium therapy, number of changes in magnesium dosage during administration, and errors associated with administration of magnesium sulphate.

After the chart review, an interdisciplinary failure mode and effect analysis was completed to identify potential system failures and the preventive measures necessary to avoid errors related to administration of magnesium sulphate. ${ }^{6}$ Failure mode and effect analysis is one strategy for improving patient safety that is recommended in the Managing Obstetrical Risk Efficiently (MOREOB) program, which has been endorsed by the Society of Obstetricians and Gynaecologists of Canada.

\section{RESULTS}

The charts for 230 patients were screened; of these, 76 patients had received magnesium sulphate at the authors' hospital between December 2004 and December 2007. Although equal numbers of charts were screened for the 2 time periods of interest, magnesium sulphate was used less often between July 2006 and December 2007 than it was between December 2004 and June 2006; as such, the numbers of patients in the study groups differed. A total of 31 patients met the date criterion for the new administration protocol group (received magnesum sulphate between July 2006 and December 2007), and 45 met the date criterion for the old administration protocol group (received magnesum sulphate between December 2004 and June 2006). However, 2 of the patients in the new protocol group had been treated in the intensive care unit, where they had received magnesium sulphate according to the old protocol; these patients were therefore included in the old administration protocol group. As such, for the purposes of analysis, there were 47 patients in the old administration protocol group and 29 in the new administration protocol group (Table 1). The mean age of the patients was 29.1 and 29.6 years, respectively. Two patients in each group had experienced seizures before treatment with magnesium sulphate. The remaining patients received magnesium sulphate for prophylaxis of eclampsia, and no patients experienced seizures after starting magnesium sulphate. All patients received the drug through a peripheral IV line.

No evidence of phlebitis was documented for any of the 76 patients. For one patient in the old administration protocol group, extravasation of IV solution into surrounding tissue was reported, but this problem did not occur in the new administration protocol group. Signs or symptoms of magnesium toxicity were not evident in any of the charts reviewed. Deep tendon reflexes were present in all cases. Although oxygen saturation was not consistently assessed during the study period, no obvious cases of respiratory depression were documented. Calcium gluconate was administered to 3 patients: 2 in the old administration protocol group and 1 in the new administration protocol group. However, all of these patients had received calcium gluconate to treat documented hypocalcemia, not magnesium toxicity. The highest serum concentration of magnesium was $3.5 \mathrm{mmol} / \mathrm{L}$, which was observed in a patient in the old administration protocol group.

There were 2 documented errors associated with failure to reset the pump after the loading dose in the old administration protocol group. One patient received $7.2 \mathrm{~g}$ of magnesium sulphate over $70 \mathrm{~min}$ when the pump was mistakenly left to infuse at the bolus rate. The charting was less clear for the second patient, who may have received up to $12 \mathrm{~g}$ of magnesium sulphate in $1 \mathrm{~h}$. A change in dose and/or concentration of the solution was made for $34(72 \%)$ of the patients in the old protocol group and $10(34 \%)$ of those in the new protocol group. One documented error in the old administration protocol group and one possible error in the new administration protocol group were associated with order changes. In the first instance (old protocol), there was an order to double the concentration of magnesium sulphate to reduce fluid intake; however, the rate was not adjusted on the pump. This patient received $4 \mathrm{~g} / \mathrm{h}$ for $7 \mathrm{~h}$, instead of the intended $2 \mathrm{~g} / \mathrm{h}$. In the second case (new protocol), the patient's dose was increased to $1.5 \mathrm{~g} / \mathrm{h}$. However, there was no documentation that $10 \mathrm{~mL}$ of D5W was added to the $50 \mathrm{~mL}$ of $20 \%$ magnesium sulphate solution, and the patient may have received $1.8 \mathrm{~g} / \mathrm{h}$ for up to $5 \mathrm{~h}$. None of these errors resulted in any documented harm to patients.

The interdisciplinary failure mode and effect analysis identified the following strategies to improve the safety of administration of magnesium sulphate: development of preprinted orders (Appendix 1), use of 20\% magnesium sulphate for all infusion rates, change to the pump settings to enable fractional infusion rates, preparation of magnesium sulphate mini-bags in the pharmacy, double-check of pump settings by a registered 
Table 1. Characteristics of Patients and of Administration Practices and Outcomes for Magnesium Sulphate

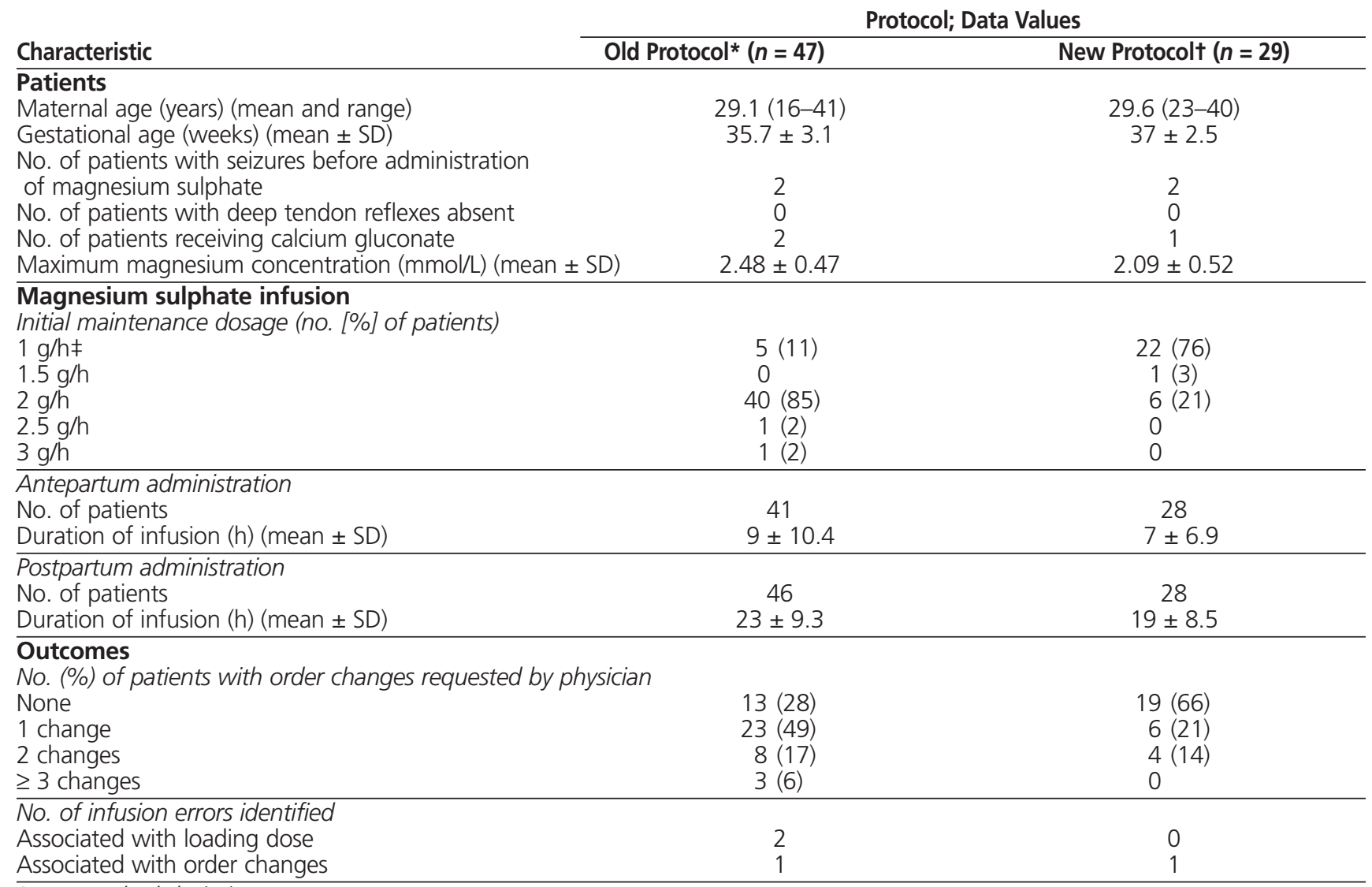

$\mathrm{SD}=$ standard deviation.

*In effect from December 2004 to June 2006.

†In effect from July 2006 to December 2007.

\#Recommended in the British Columbia Reproductive Care Program guideline, 2006. ${ }^{1}$

nurse, anesthesiology consult to ensure that the anesthetist is aware of the patient's condition and the need for fluid restriction, and distribution of protocols to all areas in the hospital to limit errors associated with patient transfers.

\section{DISCUSSION}

There were no documented cases of phlebitis in this small retrospective study of obstetric patients receiving magnesium sulphate. Searches of the MEDLINE (1996 to 2009), EMBASE (1996 to 2009), and Academic Search Complete (1996 to 2009) databases were performed with the subject headings "magnesium sulphate" and "phlebitis". Google was used to search the Internet, with the search term "magnesium sulphate protocol". No literature confirming vein irritation due to administration of highly concentrated magnesium sulphate was found, although dilute solutions of magnesium sulphate have been recommended to avoid the risk of phlebitis. ${ }^{7}$ However, the search yielded 2 Australian protocols that used undiluted 50\% magnesium sulphate for bolus and maintenance infusions for prophylaxis of seizures in patients with severe pre-eclampsia. ${ }^{8,9}$
Administration of the maintenance dose of magnesium sulphate from the same bag as the bolus dose has resulted in lethal overdoses. ${ }^{5}$ In the study reported here, 2 patients in the old administration protocol group received overdoses due to failure to reset the pump after the bolus dose. Fortunately, neither patient experienced any documented adverse effects. Additionally, the use of large volumes containing 20 to $80 \mathrm{~g}$ of magnesium sulphate increases the risk that this amount of drug will be infused if the pump is set incorrectly. In the new administration protocol group, separate bags were used for the loading and maintenance doses, which prevented overdoses with the bolus infusion rate. In addition, following full assessment of the patient's condition before bag changes, a maximum of $10 \mathrm{~g}$ of drug was added at a time to minimize the possibility of lethal overdose.

In this study, 2 administration errors, 1 in each group, occurred with changes in rate or concentration of the solution. One patient in the old protocol group received $28 \mathrm{~g}$ of magnesium sulphate over $7 \mathrm{~h}$ instead of the intended $14 \mathrm{~g}$ because the pump was not reset when the concentration was doubled. No adverse effects were documented for this patient, but this error 
had the potential to cause harm. A patient in the new administration protocol group may have received $9 \mathrm{~g}$ of magnesium sulphate instead of $7.5 \mathrm{~g}$, as dilution of the magnesium sulphate was not documented in the chart. The dilution was required for the specified infusion rate because at the time the pump was not able to deliver fractional infusion rates. This error was unlikely to have resulted in harm. However, unnecessary variability in drug concentrations and rate changes complicates infusion programming and increases the risk of patient harm. ${ }^{10,11}$ With the change from the old to the new administration protocol, the proportion of women with no changes to their orders increased from 13/47 (28\%) to 19/29 (66\%), and the proportion of patients with multiple changes declined (Table 1). Although there was no dose standardization with either of the protocols, the 2006 BCRCP guidelines limited dose changes for magnesium sulphate, recommending a maintenance dose of $1 \mathrm{~g} / \mathrm{h}$ and an increase to $1.5 \mathrm{~g} / \mathrm{h}$ only for patients with recurrent seizures. ${ }^{1}$ The lower number of changes observed for the new administration protocol group may be associated with adoption of the provincial guidelines and could lead to a reduction in errors occurring with administration of magnesium sulphate. Preprinted orders may standardize care further and may reduce unnecessary rate changes and potential errors.

Although limited by its retrospective design, small sample size, and inconsistent documentation in the charts, this study helped the authors to identify several processes that were vulnerable to human error. The study results were used to inform a failure mode and effect analysis, which allowed development of system defences to reduce the likelihood of error during administration of magnesium sulphate. One of the strategies identified was to use a single standard concentration for all infusion rates. At the authors' site, this required a change in the pump settings to allow fractional infusion rates. A double-check of pump settings by a nurse was also instituted. Errors and delays in administration might be further reduced if pharmacies or manufacturers could prepare the magnesium sulphate in ready-to-administer mini-bags, so that it could be made available as ward stock. ${ }^{4,5}$ Recently, the authors evaluated the stability of magnesium sulphate $20 \%$ in ViaFlex bags (Baxter Intravia Containers, Deerfield, Illinois). ${ }^{12}$ The solution was stable for 30 days at room temperature and 60 days in the refrigerator. The authors' pharmacy now prepares magnesium sulphate $20 \%$ in $50-\mathrm{mL}$ mini-bags, which are then readily available in the refrigerators in the birthing unit.

In conclusion, peripheral IV administration of $20 \%$ magnesium sulphate for prophylaxis of eclampsia did not result in any documented cases of phlebitis. When separate $50-\mathrm{mL}$ mini-bags of $20 \%$ magnesium sulphate were used for the loading and maintenance doses, there were no errors related to a failure to reset the pump following the loading dose. However, one potential error was identified with the new administration protocol, and a failure mode and effect analysis revealed additional processes that were vulnerable to human error. Therefore, further safety strategies were designed and implemented to reduce errors associated with administration of magnesium sulphate.

\section{References}

1. BCRCP obstetric guideline 11: hypertension in pregnancy. Vancouver (BC): British Columbia Reproductive Care Program; 2006 [cited 2008 Jul 10]. Available from: http://www.bcphp.ca//sites/bcrcp/files/Guidelines/ Obstetrics/HypertensionJune2006.pdf

2. Diagnosis, evaluation, and management of the hypertensive disorders in pregnancy [guideline 206]. J Obstet Gynaecol Can 2008 [cited 2008 Sep 27];30(3 Suppl 1):S1-S48. Available from: http://www.sogc.org/ guidelines/index_e.asp\#Obstetrics

3. Trissel LA. Handbook on injectable drugs. Bethesda (MD): American Society of Health-System Pharmacists; 2009.

4. Kohn LT, Corrigan JM, Donaldson MS, editors. To err is human: building a safer health system. Washington (DC): Institute of Medicine and National Academy Press; 2000.

5. Simpson KR, Knox GE. Obstetrical accidents involving intravenous magnesium sulfate: recommendations to promote patient safety. $M C N$ Am J Matern Child Nurs 2004;29(3):161-171.

6. Failure mode and effect analysis: Managing Obstetrical Risk Efficiently (MOREOB) program. London (ON): Salus Global Corporation; 2008 [cited 2008 Jul 14]. Available from: https://secure.moreob.com/servlets/ sfs? $\mathrm{t}=/$ contentManager/onStory \&e $=\mathrm{UTF}-8 \& \mathrm{i}=1204141627843 \&$ $1=0 \&$ active $=$ no\&sort $=$ Price $\&$ StoryID $=1206464922334$. Registration required to access content.

7. Segatore M, Stromberg TV, Lokken L. Midclavicular catheters in the antepartum population. A continuous quality improvement review. J Intraven Nurs 1998;21(5):291-300.

8. Magnesium sulphate $(\mathrm{MgSO} 4)$ infusion protocol for eclamptic seizure prophylaxis. North Sydney (Australia): New South Wales Department of Health; 2005 [cited 2008 Jul 10]. Available from: http://www.health.nsw. gov.au/policies/PD/2005/PD2005_239.html

9. Magnesium sulphate: magnesium sulphate is the anticonvulsant of choice for pre-eclampsia prophylaxis and treatment. Victoria (Australia): The Royal Women's Hospital; 2006 [cited 2008 Sep 27]. Available from: http://www.thewomens.org.au/MagnesiumSulphate

10. Bates DW, Vanderveen T, Seger DL, Yamaga C, Rothschild J. Variability in intravenous medication practices: implications for medication safety. Jt Comm J Qual Patient Saf 2005;31(4):203-210.

11. Dennison RD. High-alert drugs: strategies for safe I.V. infusions. Am Nurse Today 2006;1(2). Available from: http://www.americannursetoday.com/ Article. aspx $? \mathrm{id}=5134 \&$ fid $=5120$

12. Newby BD, Benes C, Palmer L, Cleve R. Stability of magnesium sulfate 20\% in Viaflex bags [letter]. Can J Hosp Pharm 2008;61(5):356-357.

Lynne Palmer, RN, MSN, is with the Family Birthing Unit, Surrey Memorial Hospital, Surrey, British Columbia.

Brandi D Newby, BSCPharm, ACPR, is with the Pharmacy, Surrey Memorial Hospital, Surrey, British Columbia.

\section{Address correspondence to:}

Lynne Palmer

Surrey Memorial Hospital

13750 96th Avenue

Surrey BC V3V 122

e-mail: lynne.palmer@fraserhealth.ca 
Appendix 1. Preprinted order for magnesium sulphate for severe pre-eclampsia or eclampsia. (C2008 Fraser Health. Reproduced by permission.

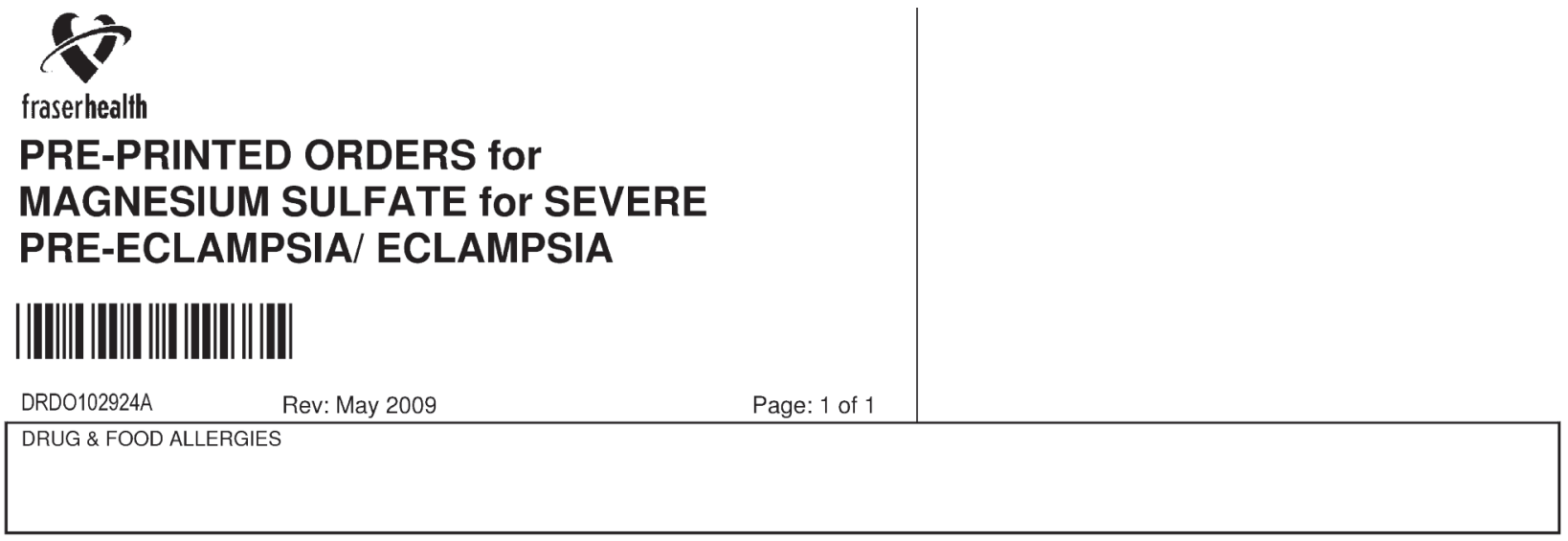

- Must Do $\square$ Optional, Physician please $(\checkmark)$ as appropriate (Physician please cross out and initial any orders not indicated)

Date: Time:

- Anaesthesiology Consult

Intravenous Therapy

- Primary IV NORMAL SALINE - adjust rate to maintain total IV intake at maximum $80 \mathrm{~mL} / \mathrm{hr}$

Baseline Assessment and Procedures

- Blood pressure, pulse, respiratory rate, temperature, deep tendon reflexes, oxygen saturation, level of consciousness (Glasgow Coma Scale)

- Apply fetal monitor to assess fetal heart rate pattern and uterine activity

- Insert foley catheter

Medications

- MAGNESIUM SULFATE $20 \%$ (10 grams/ $50 \mathrm{~mL}$ ) IV solution

- Loading dose: 4 grams (20 mL) IV over 20 minutes (infuse at $60 \mathrm{~mL} / \mathrm{hr}$ )

- Check blood pressure, pulse, respiratory rate, and deep tendon reflexes before starting maintenance infusion

- Maintenance infusion: 1 gram/ hour (infuse at $5 \mathrm{~mL} / \mathrm{hr}$ )

- If recurrent seizure:

- Stat dose: 2 grams (10 mL) IV over 10 minutes (infuse at $60 \mathrm{~mL} / \mathrm{hr}$ )

- Change maintenance infusion to: $1.5 \mathrm{grams} /$ hour (infuse at $7.5 \mathrm{~mL} / \mathrm{hr}$ )

- If urine output less than $40 \mathrm{~mL} / \mathrm{hr}$, hold NSAIDs

Monitoring (Antepartum and Postpartum)

\begin{tabular}{|l|l|}
\hline - Continuous pulse oximetry & Less than $95 \%$ for 15 minutes \\
\hline - Hourly fluid balance (intake and urine output) & Urine output is less than $100 \mathrm{~mL}$ in 4 hours \\
\hline - Hourly blood pressure, pulse, respiratory rate & Respiratory rate is less than $12 / \mathrm{minute}$ \\
\hline - Q4h deep tendon reflexes, level of consciousness, temp & Biceps or patellar reflex is absent \\
\hline - Continuous electronic fetal monitoring until delivery & Fetal heart rate pattern is atypical or abnormal \\
\hline
\end{tabular}

Magnesium sulfate infusion should ONLY continue after reassessment q4h by physician if:

- The deep tendon reflex is present

- The respiratory rate is greater than 12 per minute

- The urine output is greater than $100 \mathrm{~mL}$ in the previous 4 hours

- If any sign of magnesium toxicity (RR less than 12 per minute, absent deep tendon reflexes, muscle weakness, slurred speech, excessive drowsiness, cardiac arrhythmia, or CNS depression)

- Stop magnesium sulfate infusion

- Notify physician

- Obtain STAT serum magnesium level 